\title{
Increased Intestinal Permeability in Patients With Short Bowel Syndrome is not Affected by Parenteral Nutrition
}

\author{
A. CINKAJZLOVÁ ${ }^{1,3}$, Z. LACINOVÁ ${ }^{1,3}$, J. KLOUČKOVÁ ${ }^{1,3}$, P. KAVÁLKOVÁ ${ }^{3}$, \\ H. KRATOCHVÍLOVÁ ${ }^{1,3}$, J. KŘÍŽOVÁ ${ }^{4}$, P. TRACHTA ${ }^{4}$, M. MRÁZ ${ }^{2,3}$, M. HALUZÍK ${ }^{1,2,3}$ \\ ${ }^{1}$ Centre for Experimental Medicine, Institute for Clinical and Experimental Medicine, Prague, \\ Czech Republic, ${ }^{2}$ Diabetes Centre, Institute for Clinical and Experimental Medicine, Prague, Czech \\ Republic, ${ }^{3}$ Institute of Medical Biochemistry and Laboratory Diagnostics, ${ }^{4}$ Third Department of \\ Medicine, General University Hospital and Charles University in Prague First Faculty of Medicine, \\ Prague, Czech Republic
}

Received February 3, 2019

Accepted April 30, 2019

Epub Ahead of Print August 19, 2019

\section{Summary}

The aim of our study was to assess the presence and degree of intestinal leakage in subjects suffering from short bowel syndrome (SBS) and its modification by parenteral nutrition. To this end we assessed circulating levels of selected makers of intestinal permeability including zonulin, fatty acid binding protein 2 (FABP-2), citrulline and glucagon-like peptide 2 (GLP-2). We also measured lipopolysaccharide binding protein (LBP) as a marker of circulating levels of lipopolysaccharide acting through the CD14 molecule. Eleven SBS and 10 age- and BMI-matched control subjects were included into the study. The effect of parenteral nutrition was assessed after 14 days, 6 and 12 months from its initiation, respectively. At baseline, SBS patients had increased gut permeability as measured by zonulin $(47.24 \pm 2.14$ vs. $39.48 \pm 1.20 \mathrm{ng} / \mathrm{ml}, \mathrm{p}=0.006)$ and LBP ( $30.32 \pm 13.25$ vs. $9.77 \pm 0.71 \mu \mathrm{g} / \mathrm{ml}, \mathrm{p}<0.001)$ compared to healthy controls. Furthermore, SBS subjects had reduced FABP-2, unchanged citrulline and increased SCD14 and GLP-2 relative to control group. Throughout the whole study period the administered parenteral nutrition had no significant effect on any of the studied parameters. Taken together, our data show that patients with short bowel syndrome have increased intestinal permeability that is not affected by parenteral nutrition.

\section{Key words}

Short bowel syndrome • Gut leakage • Gut damage • Lipopolysaccharide

\section{Corresponding author}

M. Haluzík, Institute for Clinical and Experimental Medicine, Vídeňská 1958/9, Prague 4, 140 21, Czech Republic. E-mail: halm@ikem.cz

\section{Introduction}

Short bowel syndrome (SBS) is a specific type of intestinal disorder characterized by reduced length of the gut most often due to intestinal resection resulting in malabsorption, malnutrition and water and electrolyte disturbances. The main reasons for intestinal resection include tumors, inflammatory bowel disease, postradiation changes, vascular ileus, intestinal hemorrhages and others. SBS can be classified into 3 anatomic subtypes: type 1 - end jejunostomy, type 2 - jejunocolic anastomosis and type 3 - jejunoileocolic anastomosis. Symptoms of SBS arise from inadequate absorption of nutrients, vitamins and minerals and loss of hormonal production (Donohoe and Reynolds 2010, Eça and Barbosa 2016). To our best known, the presence and rate of functional gut disruption accompanying SBS is not known and according to our hypothesis subjects with SBS will have disrupted gut barrier function and will be suffering from increased intestinal permeability. For the evaluation of gut leakage and damage we have chosen four markers - zonulin as a measure of intestinal permeability, citrulline as a reflection of functional 
enterocyte mass, fatty acid binding protein 2 (FABP-2) as a marker of intestinal damage and glucagon-like protein 2 (GLP-2) as a trophic factor for intestinal mucosa - all with different biology and effects on intestinal permeability in order to obtain a complex picture of the functional gut status in SBS subjects. Furthermore, we assessed the degree of endotoxemia in subjects with SBS using lipopolysaccharide binding protein (LBP).

Zonulin (pre-haptoglobin 2) regulates intestinal permeability by EGF receptor transactivation through proteinase-activated receptor 2 , while also acting as a hemoglobin scavenger in its cleaved two-chain form (Tripathi et al. 2009). Increased zonulin levels and its intestinal production were found in several diseases with autoimmune background such as type 1 diabetes mellitus, obesity (Moreno-Navarrete et al. 2012, Sapone et al. 2006), Crohn's disease (Malickova et al. 2017) or celiac disease (Fasano et al. 2000). The amino acid citrulline is a quantitative marker of enterocyte mass. Its plasma levels correlated with the remaining bowel length and enterocyte mass independently of nutritional and inflammatory status (Crenn et al. 2008). FABP-2 is an intestinal protein responsible for the binding and transport of lipids with long chain fatty acids. Based on human and mice studies, FABP-2 is considered a marker of intestinal damage and intestinal barrier dysfunction (Guthmann et al. 2002, Lau et al. 2016, Schellekens et al. 2014). Its increased levels were found in subjects with celiac disease and type 1 and 2 diabetes mellitus (Hoffmanova et al. 2015). GLP-2 is a protein produced along with GLP-1 by post-translational cleavage of proglucagon. GLP-2 has positive effects on structural and functional intestinal integrity (Jeppesen et al. 2011) and in experimental mouse models was shown that enhances intestinal epithelial barrier function (Benjamin et al. 2000) and reduce intestinal permeability (Hadjiyanni et al. 2009).

Lipopolysaccharide binding protein (LBP) is a protein of acute phase, which binds lipopolysaccharide (LPS) in the circulation. The LPS-LBP complex is subsequently recognized by soluble or membrane bound CD14 and binds to toll-like or other receptors on the membrane of innate immunity cells recognizing pathogen-associated molecules (Triantafilou and Triantafilou 2002). For this reason, LBP is used as a marker of LPS levels. The potentially most important source of LPS (except of acute bacterial infection) is intestine (Damms-Machado et al. 2017). As shown in several experimental models chronically increased
LPS (endotoxemia) could negatively influence a number of biological processes including IGF function, cardiovascular activity and integrity or neural system (Frimmel et al. 2016, Xie et al. 2015, Zakaria et al. 2017, Zila et al. 2015).

Although primarily symptomatic, parenteral nutrition (PEN - either total or supplementary) is the therapeutic mainstay in subjects with SBS with the aim of supplementing the organism with all necessary nutrients via the parenteral route thus by-passing the dysfunctional intestine (Nightingale 1999). A properly maintained nutritional and hydration state gives the shortened gut a chance to gradually improve its resorption capacity often leading to the reduction of symptoms and in some cases even to the resolution of the SBS itself (Pironi et al. 2016). The mechanisms behind gut adaptation in SBS are yet to be fully understood; however, the improvement in gut leakage seems to be a major candidate. In the second part of our study we therefore examined the effect of PEN on the assessed markers of intestinal permeability.

\section{Methods}

\section{Study subjects}

Eleven patients with the diagnosis of SBS after jejunal resection and 10 healthy lean subjects were included in to the study. The reasons for resections were tumors (4 subjects), post-radiation damage (3 subjects), intestinal injury caused during surgery (2 subjects), myxoma of the appendix (1 subject) and vascular ileus (1 subject). All subjects had type 1 SBS with jejunostomy and the average remaining intestinal length was $90.9 \pm 12.3 \mathrm{~cm}$. Three subjects had wound inflammation and 1 subject had urinary tract infection. Control subjects were free of any medication and had no history of obesity, diabetes mellitus or any other chronic disease. Written informed consent was signed by each subject and the studies were approved by the Human Ethics Committee, First Faculty of Medicine and General University Hospital, Prague, Czech Republic.

\section{Parenteral nutrition in SBS subjects}

All SBS subjects were treated by parenteral nutrition. Of the 11 subjects included, 5 completed the whole study, while the other 6 did not reach the 12-month mark due to reconstruction of gut continuity, death or non-compliance with study follow-up. Blood samples were taken at baseline (V1) and 14 days (V2), 6 (V3) and 12 months (V4) after initiation of parenteral nutrition. 


\section{Anthropometric examination and blood sampling}

All subject enrolled in the study underwent anthropometric examination and their BMI was calculated. Blood samples were taken after an overnight fasting and centrifuged for $10 \mathrm{~min}$ at $1000 \times \mathrm{g}$ within $30 \mathrm{~min}$ after withdrawal. Serum or plasma aliquots were subsequently stored at $-80{ }^{\circ} \mathrm{C}$.

\section{Hormonal and biochemical assays}

Serum zonulin levels were measured by ELISA kit (Immundiagnostik AG, Bensheim, Germany) with sensitivity $0.225 \mathrm{ng} / \mathrm{ml}$. Plasma FABP-2 levels were measured by ELISA kit (R\&D systems, Inc., Minneapolis, USA). Sensitivity was $6.1 \mathrm{pg} / \mathrm{ml}$. Plasma LBP levels were measured by ELISA kit (Hycult biotech, Uden, Netherlands). Sensitivity was $4.4 \mathrm{ng} / \mathrm{ml}$. Plasma soluble CD14 levels were measured by ELISA kit (Biovendor, Brno, Czech Republic). Sensitivity was $6 \mathrm{ng} / \mathrm{ml}$. Plasma GLP-2 levels were measure by ELISA kit (Merck KGaA, Darmstadt, Germany) with sensitivity $0.3 \mathrm{ng} / \mathrm{ml}$. The intra- and interassay variabilities for all ELISA assays were between 5.0 and $10.0 \%$.

Serum citrulline levels were analysed by ion exchange chromatography with ninhydrin detection on an automatic amino acid analyzer (INGOS s.r.o., Prague, Czech Republic).

Biochemical parameters (blood glucose, glycated hemoglobin $-\mathrm{HbA}_{1 \mathrm{c}}$, HDL cholesterol, total cholesterol, triglycerides and CRP levels) were measured and LDL cholesterol was calculated at the Institute of Medical Biochemistry and Laboratory Diagnostics, General University Hospital, Prague, Czech Republic by standard laboratory methods.

\section{Statistical analysis}

Statistical analysis was performed using SigmaPlot 13.0 (SPSS Inc., Chicago, IL, USA). Results are expressed as means \pm standard error of the mean (SEM). One way RM ANOVA followed by Holm-Sidak test or One way RM ANOVA on Ranks followed by Dunn's method, unpaired $t$-test or Mann-Whitney Rank Sum Test were used for the assessment of intra- and intergroup differences, as appropriate. Statistical significance was assigned to $p<0.05$. Spearman or Pearson correlation test was used to assess the association between zonulin, citrulline, FABP-2, LBP, sCD14, GLP-2 and other measured parameters. Baseline results of healthy control and SBS subjects were used for correlation tests; only analyses with significance $p<0.005$ were mentioned.

\section{Results}

Baseline characteristics of study subjects

SBS subjects had lower total, HDL and LDL cholesterol and higher triglycerides compared to healthy control group. When assessing markers of gut leakage, SBS group showed higher zonulin, LBP, sCD14 and GLP-2 levels and lower FABP-2, while citrulline levels only tended $(\mathrm{p}=0.058)$ to be lower compared to healthy control subjects (Table 1).

\section{The effect of parenteral nutrition}

Twelve months of parenteral nutrition increased body weight and nutritional parameters including albumin and transferrin, while CRP tended to be decreased (Table 2). During the study period, GLP-2 levels were reduced to a level comparable to healthy control subjects, while no significant change could be observed in other markers of gut permeability (Fig. 1).

Relationship of parameters of intestinal permeability to biochemical factors

Baseline results of the combined group of SBS subjects and healthy controls were used for correlation analyses.

FABP-2 positively correlated with total $(\mathrm{R}=0.650, \mathrm{p}=0.004)$, HDL $(\mathrm{R}=0.645, \mathrm{p}=0.004)$ and LDL cholesterol $(\mathrm{R}=0.673, \mathrm{p}=0.003)$ and inversely with LBP $(\mathrm{R}=-0.635, \mathrm{p}=0.004)$. LBP positively correlated with $\mathrm{CRP}(\mathrm{R}=0.773, \mathrm{p}=0.004)$ and $\mathrm{sCD} 14(\mathrm{R}=0.815, \mathrm{p}=0.001)$ and negatively with total $(\mathrm{R}=-0.824, \mathrm{p}<0.001)$, HDL $(\mathrm{R}=-0.839, \mathrm{p}<0.001)$ and $\mathrm{LDL}$ cholesterol $(\mathrm{R}=-0.674$, $\mathrm{p}=0.002) \quad$ and FABP-2 $\quad(\mathrm{R}=-0.635, \quad \mathrm{p}=0.004)$. No statistically significant correlations could be found in other parameters of gut leakage.

\section{Discussion}

In this study we confirmed our hypothesis that short bowel syndrome is associated with disrupted gut barrier function. Our type 1 SBS subjects had increased intestinal permeability as shown by elevated zonulin and GLP-2 levels, while FABP-2 was decreased and citrulline unchanged. SBS subjects also suffered from endotoxemia evaluated as high LBP levels positively associated with sCD14 and systemic CRP. However, we could not find any positive effects of parenteral nutrition on the assessed parameters of gut leakage.

Zonulin, also called pre-haptoglobin 2, is a potent regulator of intestinal tight junctions and is thus 
used as a marker of intestinal permeability (Fasano et al. 2000). Increased zonulin levels and its intestinal production were found in several diseases associated with proinflammatory status such as type 1 diabetes mellitus, obesity (Moreno-Navarrete et al. 2012, Sapone et al. 2006), Crohn's disease (Malickova et al. 2017) or celiac

Table 1. Anthropometric, biochemical, and hormonal characteristics of study subjects at baseline.

\begin{tabular}{|c|c|c|c|}
\hline & Controls & SBS & p-values \\
\hline Number & 10 & 11 & --- \\
\hline Gender $(m / f)$ & $6 / 4$ & $6 / 5$ & --- \\
\hline Age (year) & $53.3 \pm 1.5$ & $64.2 \pm 4.3$ & 0.120 \\
\hline Body mass index $\left(\mathrm{kg} / \mathrm{m}^{2}\right)$ & $22.6 \pm 0.7$ & $20.9 \pm 3.7$ & 0.661 \\
\hline Blood glucose $(\mathrm{mmol} / \mathrm{l})$ & $4.54 \pm 0.13$ & $5.02 \pm 0.26$ & 0.180 \\
\hline$H b A_{l c}(\mathrm{mmol} / \mathrm{l})$ & $41.2 \pm 1.42$ & $32.6 \pm 3.92 *$ & 0.037 \\
\hline Total cholesterol (mmol/l) & $5.53 \pm 0.24$ & $3.53 \pm 0.17^{*}$ & $<0.001$ \\
\hline Triglycerides (mmol/l) & $1.05 \pm 0.11$ & $1.86 \pm 0.39 *$ & 0.039 \\
\hline HDL cholesterol (mmol/l) & $1.75 \pm 0.20$ & $0.95 \pm 0.17 *$ & 0.005 \\
\hline LDL cholesterol (mmol/l) & $3.32 \pm 0.13$ & $1.83 \pm 0.09^{*}$ & $<0.001$ \\
\hline Zonulin $(n g / m l)$ & $39.48 \pm 1.20$ & $47.24 \pm 2.14^{*}$ & 0.006 \\
\hline Citrulline ( $\mu \mathrm{mol} / \mathrm{l})$ & $32.22 \pm 2.44$ & $24.70 \pm 2.73$ & 0.058 \\
\hline$F A B P-2(n g / m l)$ & $1.24 \pm 0.10$ & $0.57 \pm 0.14^{*}$ & 0.001 \\
\hline $\operatorname{LBP}(\mu \mathrm{g} / \mathrm{ml})$ & $9.77 \pm 0.71$ & $30.32 \pm 3.99 *$ & $<0.001$ \\
\hline$s C D 14(\mu g / m l)$ & $5.39 \pm 0.36$ & $8.18 \pm 0.85^{*}$ & 0.022 \\
\hline$G L P-2(n g / m l)$ & $2.90 \pm 0.44$ & $5.74 \pm 0.79 *$ & 0.008 \\
\hline
\end{tabular}

SBS: short bowel syndrome, LBP: lipopolysaccharide binding protein, FABP-2: fatty acid binding protein 2, GLP-2: glucagon-like protein 2, NP: non-measured parameter. Values are Mean \pm SEM. $* p<0.05$ vs. Healthy control subjects, unpaired $t$-test or Mann-Whitney Rank Sum Test.

Table 2. The effect of parenteral nutrition on anthropometric, biochemical, and hormonal characteristics of subjects with short bowel syndrome.

\begin{tabular}{lcccc}
\hline & V1 & V2 & V3 & V4 \\
\hline Number & 11 & 9 & 5 & 5 \\
Body mass index $\left(\mathrm{kg} / \mathrm{m}^{2}\right)$ & $20.9 \pm 3.7$ & $25.9 \pm 2.3$ & $25.0 \pm 1.2$ & $28.1 \pm 3.0$ \\
Blood glucose $(\mathrm{mmol} / \mathrm{l})$ & $5.02 \pm 0.26$ & $5.68 \pm 0.28$ & $5.75 \pm 0.83$ & $5.38 \pm 0.35$ \\
HbA $A_{l \text { (mmol/l) }}$ & $32.6 \pm 3.92$ & $\mathrm{NP}$ & $\mathrm{NP}$ & $33.20 \pm 1.24^{*}$ \\
Total cholesterol $(\mathrm{mmol} / \mathrm{l})$ & $3.53 \pm 0.17^{*}$ & $3.99 \pm 0.37 *$ & $2.83 \pm 0.30^{*}$ & $4.11 \pm 0.27^{*}$ \\
Triglycerides $(\mathrm{mmol} / \mathrm{l})$ & $1.86 \pm 0.39$ & $1.58 \pm 0.36$ & $1.64 \pm 0.32$ & $2.21 \pm 0.54$ \\
HDL cholesterol $(\mathrm{mmol} / \mathrm{l})$ & $0.95 \pm 0.17^{*}$ & $0.85 \pm 0.19$ & $0.89 \pm 0.24$ & $1.36 \pm 0.35$ \\
LDL cholesterol $(\mathrm{mmol} / \mathrm{l})$ & $1.83 \pm 0.09^{*}$ & $2.07 \pm 0.17 *$ & $1.78 \pm 0.12^{*}$ & $1.62 \pm 0.32^{*}$ \\
Total protein $(\mathrm{g} / \mathrm{l})$ & $60.7 \pm 3.1$ & $69.7 \pm 1.2$ & $73.9 \pm 4.0$ & $72.5 \pm 3.6$ \\
Albumin $(\mathrm{g} / \mathrm{l})$ & $26.9 \pm 1.4$ & $31.7 \pm 3.1$ & $33.6 \pm 4.2$ & $38.9 \pm 1.6^{\mathbf{1}}$ \\
Prealbumin $(\mathrm{g} / \mathrm{l})$ & $0.217 \pm 0.019$ & $0.242 \pm 0.029$ & $0.245 \pm 0.031$ & $0.264 \pm 0.028$ \\
Transferrin $(\mathrm{g} / \mathrm{l})$ & $1.953 \pm 0.227$ & $2.125 \pm 0.375$ & $2.398 \pm 0.359$ & $2.572 \pm 0.279^{1}$ \\
CRP $($ mg/l) & $57.17 \pm 16.53$ & $45.24 \pm 20.16$ & $43.15 \pm 18.42$ & $13.04 \pm 4.70$ \\
Leukocytes $\left(10^{9} / \mathrm{l}\right)$ & $9.09 \pm 1.06$ & $10.0 \pm 1.73$ & $8.08 \pm 1.97$ & $7.15 \pm 1.67$ \\
\hline
\end{tabular}

CRP: C-reactive protein, NP: non-measured parameter. V1: before realimentation, V2: 14 days after realimentation, V3: 6 months after realimentation, V4: 12 months after realimentation. Values are Mean \pm SEM. ${ }^{*} p<0.05$ vs. Healthy control subjects. ${ }^{1} p<0.05$ vs. V1. 

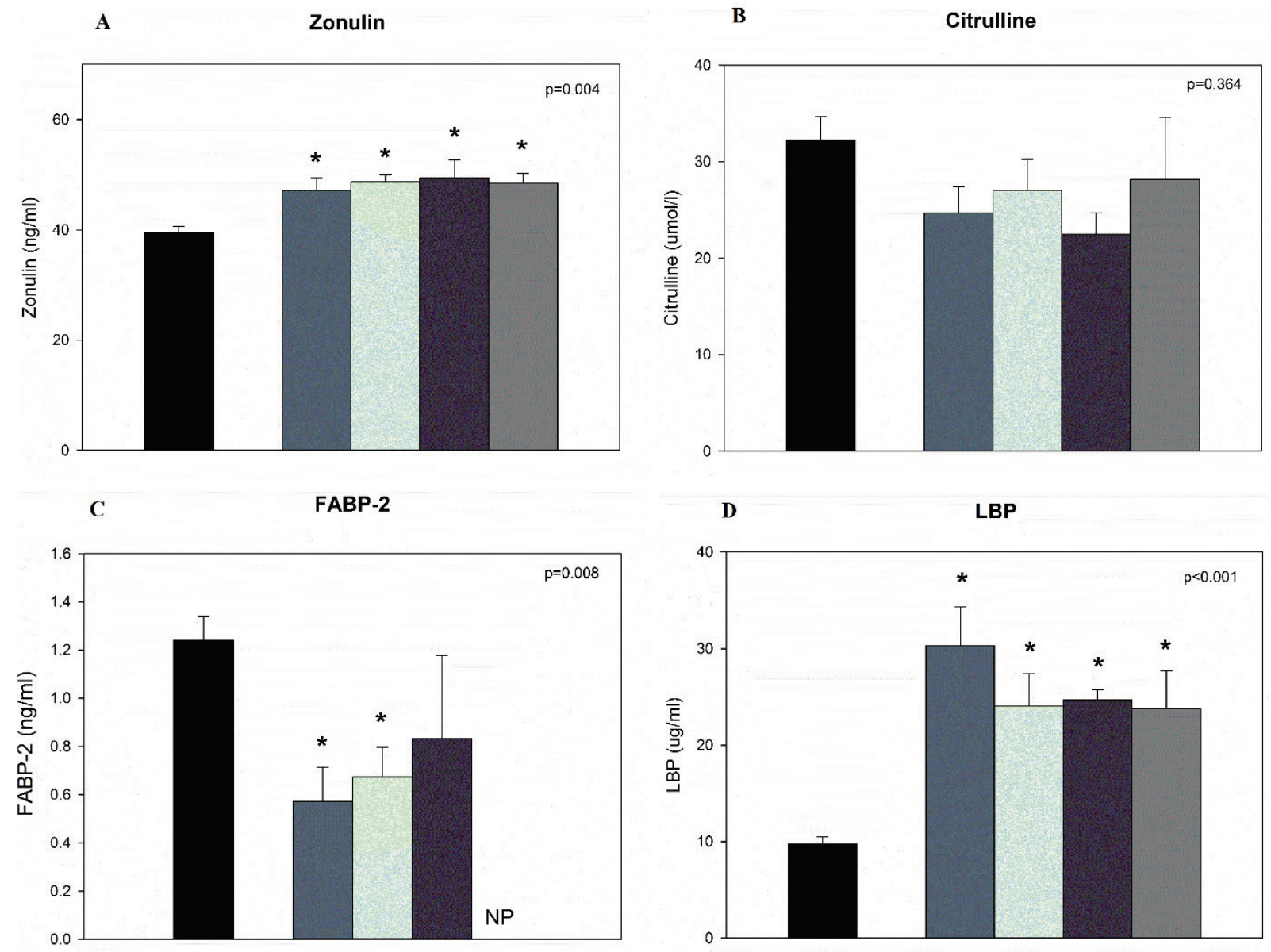

E

sCD14

F

GLP-2
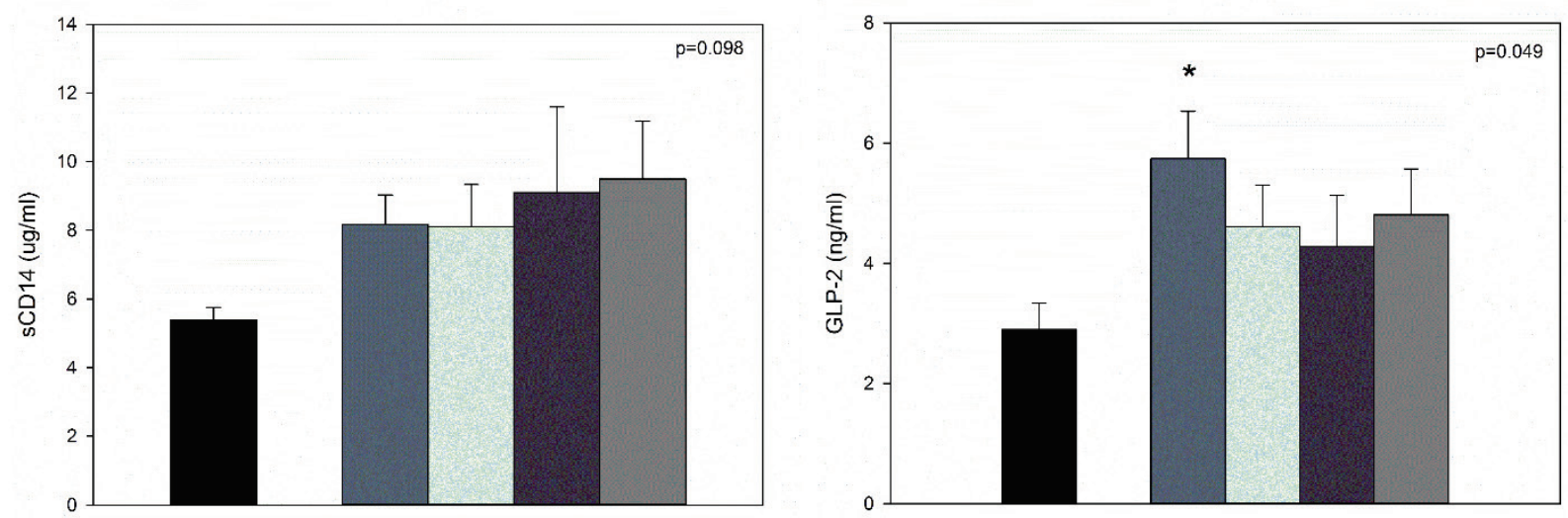

Healthy control subjects

After hospitalization

14 days of parenteral nutrition

6 months of parenteral nutrition

12 months of parenteral nutrition

Fig. 1. The effect of parenteral nutrition in SBS patients on zonulin (A), citrulline (B), fatty acid binding protein (C), lipopolysaccharide binding protein (D), soluble CD14 (E) and glucagon-like protein 2 (F) levels. NP: non-measured parameter. Values are Mean \pm SEM. $* p<0.05$ vs. healthy control subjects; One way ANOVA/ANOVA on Ranks; ( $p$ values for ANOVA are displayed on graphs). No significant changes were due to parenteral nutrition, in all cases $p>0.05$, One way Repeat Measurements ANOVA/ Repeat Measurements ANOVA on Ranks. 
disease (Fasano et al. 2000). Moreover, zonulin transgenic mice characterized by increased gut leakage showed increased mortality and morbidity compared with their wild type littermates (Sturgeon et al. 2017). In our SBS subjects, zonulin levels were significantly increased, confirming thus the suggested association between SBS and increased intestinal permeability. Interestingly, parenteral nutrition did not change zonulin concentrations throughout the whole study period suggesting that in spite of the overall improvement in nutritional status intestinal permeability of the short bowel still remained increased.

GLP-2, a product of posttranslational proglucagon cleavage, was shown to have trophic and anti-inflammatory intestinal effects and treatment with its analogue teduglutide was associated with enhancement or restoration of the structural and functional intestinal integrity (Jeppesen et al. 2011). In our study, subjects with SBS had higher GLP-2 levels compared to healthy controls at baseline, while parenteral nutrition decreased them to almost comparable values. Increased GLP-2 levels might comprise a compensatory response to SBS, which might fade away in the course of gut adaptation. However, the basal increase in GLP-2 is somehow puzzling considering its production site - the L cells being predominantly localized in the ileum, which in our type 1 SBS subjects with terminal jejunostomy was not functionally present at all (Holst 2007). Although some L cells can be also present in the jejunum or even duodenum, this finding will certainly require further elucidation (Drucker and Nauck 2006).

FABP-2, considered a sensitive marker of gut damage (Kanda et al. 1996, Vermeulen Windsant et al. 2012), was shown to be increased in subjects with celiac disease and type 1 and 2 diabetes mellitus (Hoffmanova et al. 2015). Here we surprisingly found decreased levels of FABP-2 in SBS subjects with jejunostomy, while parenteral nutrition was associated with an increase in FABP-2. This discrepancy might most probably be attributed to the jejunoileal resection present in all subjects leading thus to a significant loss in FABP-2 production site (Levy et al. 2009). FABP-2 further positively correlated with total, LDL and HDL cholesterol, which is probably related to its physiological function to bind and transfer fatty acids with long chain (Furuhashi and Hotamisligil 2008).

Citrulline is a quantitative marker of enterocyte mass and intestinal absorption previously assessed in SBS subjects (Jianfeng et al. 2005, Santarpia et al. 2008). In our SBS group, citrulline tended to reduced values relative to healthy controls, even though the difference did not reach statistical significance. Similarly to zonulin, parenteral nutrition had no effect on citrulline levels, corroborating its relatively small effect on intestinal adaptation in our study.

One of the reasons for the insufficient effect of parenteral nutrition on parameters of gut leakage and adaptation in our study might be the increased values of lipopolysaccharide-binding protein (LBP) - albeit with a reduction trend in the course of the study - suggesting high circulating lipopolysaccharide (LPS) concentrations. This could be related to slower and inefficient gut healing as shown in a mice SBS model where LPS endotoxemia led to reduced cell proliferation and enterocyte apoptosis thus inhibiting intestinal adaptation in contrast to untreated SBS animals (Sukhotnik et al. 2002). Moreover, experimental results using ex vivo mammalian small intestines and intestinal cell monolayers showed increased production of zonulin due to exposition to pathogenic and non-pathogenic enterobacteria in which LPS forms an integral part of their plasmatic membrane (El Asmar et al. 2002). A strong correlation between LPB and CRP levels in our subjects further underlines its association with inflammatory status. In contrast, the negative association between LBP and HDL cholesterol found in SBS patients was partly expected because of the ability of HDL cholesterol to detoxify and neutralize LPS molecules (Jayashree et al. 2014). As expected, LBP levels were positively associated with sCD14 as LPS biological actions are mediated through CD14 binding. While basal sCD14 levels were higher in SBS subjects, no significant changes between SBS and healthy control subjects were seen during the 12-month course of parenteral nutrition. The discrepancy between increased LBP levels and unchanged SCD14 could be caused by the fact that LPS acts through circulatory as well as membrane form of CD14 (Triantafilou and Triantafilou 2002).

The main limitations of our study include the relatively low number of study participants and the low completion rate of the whole parenteral nutrition follow-up period. Also, more than a third of the SBS subjects had inflammatory complications during the study. These factors could be partially responsible for discrepancies between anticipated and observed results and for the absence of a statistically significant effect of parenteral nutrition on assessed parameters; however, as newly diagnosed SBS syndrome is relatively rare and their longer-term survival is limited by underlying 
comorbidities, we were not able to include more subjects or exclude any of the enrolled patients from the analysis due to inflammatory or other complications.

Taken together, zonulin seems to be the best marker for the evaluation of intestinal permeability and functional damage of the gut in subjects with type 1 short bowel syndrome not depending on nutrient absorption, type of resection or inflammatory status. In contrast, FABP-2 levels seem to be influenced more by the extent of jejunal resection, while citrulline failed to show any significant changes. Besides that, gut renewal and adaptation could be negatively influenced by endotoxemia which to some extent persisted even after 1 year of parenteral nutrition. Finally, despite markedly improving nutritional status, parenteral nutrition did not positively influence any of the assessed markers of intestinal permeability.

\section{Conflict of Interest}

There is no conflict of interest.

\section{Acknowledgements}

The study was supported by Ministry of Health of the Czech Republic, grant No 15-27863A.

\section{References}

BENJAMIN MA, MCKAY DM, YANG PC, CAMERON H, PERDUE MH: Glucagon-like peptide-2 enhances intestinal epithelial barrier function of both transcellular and paracellular pathways in the mouse. Gut 47: 112-119, 2000.

CRENN P, MESSING B, CYNOBER L: Citrulline as a biomarker of intestinal failure due to enterocyte mass reduction. Clin Nutr 27: 328-339, 2008.

DAMMS-MACHADO A, LOUIS S, SCHNITZER A, VOLYNETS V, RINGS A, BASRAI M, BISCHOFF SC: Gut permeability is related to body weight, fatty liver disease, and insulin resistance in obese individuals undergoing weight reduction. Am J Clin Nutr 105: 127-135, 2017.

DONOHOE CL, REYNOLDS JV: Short bowel syndrome. Surgeon 8: 270-279, 2010.

DRUCKER DJ, NAUCK MA: The incretin system: glucagon-like peptide-1 receptor agonists and dipeptidyl peptidase4 inhibitors in type 2 diabetes. Lancet 368: 1696-1705, 2006.

EÇA R, BARBOSA E: Short bowel syndrome: treatment options. J Coloproctol 36: 262-272, 2016.

EL ASMAR R, PANIGRAHI P, BAMFORD P, BERTI I, NOT T, COPPA GV, CATASSI C, FASANO A: Host-dependent zonulin secretion causes the impairment of the small intestine barrier function after bacterial exposure. Gastroenterology 123: 1607-1615, 2002.

FASANO A, NOT T, WANG W, UZZAU S, BERTI I, TOMMASINI A, GOLDBLUM SE: Zonulin, a newly discovered modulator of intestinal permeability, and its expression in coeliac disease. Lancet 355: 1518-1519, 2000.

FRIMMEL K, SOTNIKOVA R, NAVAROVA J, BERNATOVA I, KRIZAK J, HAVIAROVA Z, KURA B, SLEZAK J, OKRUHLICOVA L: Omega-3 fatty acids reduce lipopolysaccharide-induced abnormalities in expression of connexin-40 in aorta of hereditary hypertriglyceridemic rats. Physiol Res 65 (Suppl 1): S65-S76, 2016.

FURUHASHI M, HOTAMISLIGIL GS: Fatty acid-binding proteins: role in metabolic diseases and potential as drug targets. Nat Rev Drug Discov 7: 489-503, 2008.

GUTHMANN F, BORCHERS T, WOLFRUM C, WUSTRACK T, BARTHOLOMAUS S, SPENER F: Plasma concentration of intestinal- and liver-FABP in neonates suffering from necrotizing enterocolitis and in healthy preterm neonates. Mol Cell Biochem 239: 227-234, 2002.

HADJIYANNI I, LI KK, DRUCKER DJ: Glucagon-like peptide-2 reduces intestinal permeability but does not modify the onset of type 1 diabetes in the nonobese diabetic mouse. Endocrinology 150: 592-599, 2009.

HOFFMANOVA I, SANCHEZ D, HABOVA V, ANDEL M, TUCKOVA L, TLASKALOVA-HOGENOVA H: Serological markers of enterocyte damage and apoptosis in patients with celiac disease, autoimmune diabetes mellitus and diabetes mellitus type 2. Physiol Res 64: 537-546, 2015.

HOLST JJ: The Physiology of glucagon-like peptide 1. Physiol Rev 87: 1409-1439, 2007. 
JAYASHREE B, BIBIN YS, PRABHU D, SHANTHIRANI CS, GOKULAKRISHNAN K, LAKSHMI BS, MOHAN V, BALASUBRAMANYAM M: Increased circulatory levels of lipopolysaccharide (LPS) and zonulin signify novel biomarkers of proinflammation in patients with type 2 diabetes. Mol Cell Biochem 388: 203-210, 2014.

JEPPESEN P, GILROY R, PERTKIEWICZ M, ALLARD JP, MESSING B, O'KEEFE SJ: Randomised placebocontrolled trial of teduglutide in reducing parenteral nutrition and/or intravenous fluid requirements in patients with short bowel syndrome. Gut 60: 902-914, 2011.

JIANFENG G, WEIMING Z, NING L, FANGNAN L, LI T, NAN L, JIESHOU L: Serum citrulline is a simple quantitative marker for small intestinal enterocytes mass and absorption function in short bowel patients. J Surg Res 127: 177-182, 2005.

KANDA T, FUJII H, TANI T, MURAKAMI H, SUDA T, SAKAI Y, ONO T, HATAKEYAMA K: Intestinal fatty acid-binding protein is a useful diagnostic marker for mesenteric infarction in humans. Gastroenterology 110: 339-343, 1996.

LAU E, MARQUeS C, PeStana D, SANTOALHA M, CARVAlHo D, FReitas P, CALHAU C: The role of I-FABP as a biomarker of intestinal barrier dysfunction driven by gut microbiota changes in obesity. Nutr Metab (Lond) 13: 31, 2016.

LEVY E, MÉNARD D, DELVIN E, MONTOUDIS A, BEAULIEU JF, MAILHOT G, DUBÉ N, SINNETT D, SEIDMAN E, BENDAYAN M: Localization, function and regulation of the two intestinal fatty acid-binding protein types. Histochem Cell Biol 132: 351-367, 2009.

MALICKOVA K, FRANCOVA I, LUKAS M, KOLAR M, KRALIKOVA E, BORTLIK M, DURICOVA D, STEPANKOVA L, ZVOLSKA K, PANKOVA A, ZIMA T: Fecal zonulin is elevated in Crohn's disease and in cigarette smokers. Pract Lab Med 9: 39-44, 2017.

MORENO-NAVARRETE JM, SABATER M, ORTEGA F, RICART W, FERNANDEZ-REAL JM: Circulating zonulin, a marker of intestinal permeability, is increased in association with obesity-associated insulin resistance. PLoS One 7: e37160, 2012.

NIGHTINGALE JMD: Management of patients with a short bowel. Nutrition 15: 633-637, 1999.

PIRONI L, ARENDS J, BOZZETTI F, CUERDA C, GILLANDERS L, JEPPESEN PB, JOLY F, KELLY D, LAL S, STAUN M, SZCZEPANEK K, VAN GOSSUM A, WANTEN G, SCHNEIDER SM: ESPEN guidelines on chronic intestinal failure in adults. Clin Nutr 35: 247-307, 2016.

SANTARPIA L, CATANZANO F, RUOPPOLO M, ALFONSI L, VITALE DF, PECCE R, PASANISI F, CONTALDO F, SALVATORE F: Citrulline blood levels as indicators of residual intestinal absorption in patients with short bowel syndrome. Ann Nutr Metab 53: 137-142, 2008.

SAPONE A, DE MAGISTRIS L, PIETZAK M, CLEMENTE MG, TRIPATHI A, CUCCA F, LAMPIS R, KRYSZAK D, CARTENI M, GENEROSO M, IAFUSCO D, PRISCO F, LAGHI F, RIEGLER G, CARRATU R, COUNTS D, FASANO A: Zonulin upregulation is associated with increased gut permeability in subjects with type 1 diabetes and their relatives. Diabetes 55: 1443-1449, 2006.

SCHELLEKENS DH, GROOTJANS J, DELLO SA, VAN BIJNEN AA, VAN DAM RM, DEJONG CH, DERIKX JP, BUURMAN WA: Plasma intestinal fatty acid-binding protein levels correlate with morphologic epithelial intestinal damage in a human translational ischemia-reperfusion model. J Clin Gastroenterol 48: 253-260, 2014.

STURGEON C, LAN J, FASANO A: Zonulin transgenic mice show altered gut permeability and increased morbidity/mortality in the DSS colitis model. Ann N Y Acad Sci 1397: 130-142, 2017.

SUKHOTNIK I, YAKIREVICH E, CORAN AG, SIPLOVICH L, KRAUSZ M, SABO E, KRAMER A, SHILONI E: Lipopolysaccharide endotoxemia reduces cell proliferation and decreases enterocyte apopotosis during intestinal adaptation in a rat model of short-bowel syndrome. Pediatr Surg Int 18: 615-619, 2002.

TRIANTAFILOU M, TRIANTAFILOU K: Lipopolysaccharide recognition: CD14, TLRs and the LPS-activation cluster. Trends Immunol 23: 301-304, 2002.

TRIPATHI A, LAMMERS KM, GOLDBLUM S, SHEA-DONOHUE T, NETZEL-ARNETT S, BUZZA MS, ANTALIS TM, VOGEL SN, ZHAO A, YANG S, ARRIETTA MC, MEDDINGS JB, FASANO A: Identification of human zonulin, a physiological modulator of tight junctions, as prehaptoglobin-2. Proc Natl Acad Sci U S A 106: 16799-16804, 2009. 
VERMEULEN WINDSANT IC, HELLENTHAL FA, DERIKX JP, PRINS MH, BUURMAN WA, JACOBS MJ, SCHURINK GW: Circulating intestinal fatty acid-binding protein as an early marker of intestinal necrosis after aortic surgery: a prospective observational cohort study. Ann Surg 255: 796-803, 2012.

XIE ZL, YE PS, ZHANG SK, ZHANG YS, SHEN XZ: Endogenous LPS alters liver GH/IGF system gene expression and plasma lipoprotein lipase in goats. Physiol Res 64: 721-729, 2015.

ZAKARIA R, WAN YAACOB WM, OTHMAN Z, LONG I, AHMAD AH, AL-RAHBI B: Lipopolysaccharideinduced memory impairment in rats: a model of Alzheimer's disease. Physiol Res 66: 553-565, 2017.

ZILA I, MOKRA D, KOPINCOVA J, KOLOMAZNIK M, JAVORKA M, CALKOVSKA A: Heart rate variability and inflammatory response in rats with lipopolysaccharide-induced endotoxemia. Physiol Res 64 (Suppl 5): S669-S676, 2015. 